\title{
Estradiol Facilitates the Release of Neuropeptide Y to Suppress Hippocampus-Dependent Seizures
}

\author{
Veronica A. Ledoux, ${ }^{\star}$ Tereza Smejkalova, ${ }^{\star}$ Renee M. May, Bradley M. Cooke, and Catherine S. Woolley \\ Department of Neurobiology and Physiology, Northwestern University, Evanston, Illinois 60208
}

\begin{abstract}
About one-third of women with epilepsy have a catamenial seizure pattern, in which seizures fluctuate with the menstrual cycle. Catamenial seizures occur more frequently when the ratio of circulating estradiol to progesterone is high, suggesting that estradiol is proconvulsant. We used adult female rats to test how estradiol-induced suppression of GABAergic inhibition in the hippocampus affects behavioral seizures induced by kainic acid. As expected, estradiol decreased the latency to initiate seizures, indicating increased seizure susceptibility. At the same time, however, estradiol also shortened the duration of late-stage seizures, indicating decreased seizure severity. Additional analyses showed that the decrease in seizure severity was attributable to greater release of the anticonvulsant neuropeptide, neuropeptide Y (NPY). First, blocking hippocampal NPY during seizures eliminated the estradiol-induced decrease in seizure duration. Second, light and electron microscopic studies indicated that estradiol increases the potentially releasable pool of NPY in inhibitory presynaptic boutons and facilitates the release of NPY from inhibitory boutons during seizures. Finally, the presence of estrogen receptor- $\alpha$ on large dense-core vesicles (LDCVs) in the hippocampus suggests that estradiol could facilitate neuropeptide release by acting directly on LDCVs themselves. Understanding how estradiol regulates NPY-containing LDCVs could point to molecular targets for novel anticonvulsant therapies.
\end{abstract}

Key words: catamenial epilepsy; CA1; GABA; large dense-core vesicle; kainic acid; electron microscopy

\section{Introduction}

In $\sim 30 \%$ of women with epilepsy, seizures fluctuate with the menstrual cycle, termed catamenial epilepsy. Catamenial seizures occur more frequently when the ratio of circulating estradiol to progesterone is high (Backstrom, 1976), resulting in at least a doubling of seizure frequency during the preovulatory or perimenstrual periods (Herzog et al., 1997). This relationship has led to the relatively simple idea that estradiol is generally proconvulsant, whereas progesterone is generally anticonvulsant. Animal studies consistently support anticonvulsant effects of progesterone, primarily through $\mathrm{GABA}_{\mathrm{A}}$ receptor modulation (Smith et al., 1998; Kaminski et al., 2004). Evidence for the proconvulsant effects of estradiol, however, is more equivocal.

Some animal studies find that estradiol increases seizure susceptibility, whereas others report no effect (for review, see Veliskova, 2006). These contradictions may arise from differences in estradiol treatment before seizure testing, among the brain regions involved in different types of seizures, and/or in the aspects of seizures that are measured. For example, studies in rats show that duration of estradiol exposure is critical in determining its cellular and synaptic effects in the neural circuits that support

\footnotetext{
Received Sept. 30, 2008; revised Dec. 15, 2008; accepted Dec. 19, 2008.

This work was supported by National Institute of Neurological Disorders and Stroke Grant NS037324, Nationa Institute of Mental Health Grant MH067564, and National Center for Research Resources Grant RR015497; by The W. M. Keck Foundation; and by the Northwestern University Biological Imaging Facility.

*V.A.L. and T.S. contributed equally to this work.

Correspondence should be addressed to Catherine S. Woolley, 2205 Tech Drive, Northwestern University, Evanston, IL 60208. E-mail: cwoolley@northwestern.edu.

DOI:10.1523/JNEUROSCI.4688-08.2009

Copyright $\odot 2009$ Society for Neuroscience $\quad 0270-6474 / 09 / 291457-12 \$ 15.00 / 0$
}

seizure activity, such as in the hippocampus (Rudick and Woolley, 2001). Thus, understanding how estradiol influences seizures requires thorough behavioral evaluation under conditions in which its neuronal and synaptic effects are well characterized.

Much of this groundwork has been done for estradiol's effects on seizures that depend on the hippocampus. The hippocampus is frequently a focus of seizure activity in temporal lobe epilepsy, the most common form of epilepsy in adulthood, and the effects of estradiol on hippocampal synapses have been studied extensively (Woolley and McEwen, 1992; Adams et al., 2001; Rudick and Woolley, 2001; Yankova et al., 2001; Rudick et al., 2003; Ledoux and Woolley, 2005; Smith and McMahon, 2005). Our previous electrophysiological and ultrastructural studies in rats show that $24 \mathrm{~h}$ of estradiol treatment suppresses GABAergic inhibitory synaptic transmission in the hippocampus by decreasing GABA release, without affecting excitatory synapses. Estradiol decreases the amplitude of synaptically evoked IPSCs, the frequency but not amplitude of miniature IPSCs (Rudick and Woolley, 2001), paired-pulse depression of evoked IPSCs (Rudick et al., 2003), and the number of vesicles docked at inhibitory synapses (Ledoux and Woolley, 2005). Each of these changes occurs in the absence of any effect on excitatory postsynaptic currents.

Here, we used acute kainic acid (KA) treatment to investigate how estradiol-induced changes in inhibitory synapses in the hippocampus influence hippocampus-dependent behavioral seizures. Systemic KA causes a series of progressively more severe, highly stereotyped behavioral seizures that originate in the hippocampus (Lothman and Collins, 1981; Zeng et al., 2007). As described below, we found that $24 \mathrm{~h}$ of estradiol treatment in- 
creases susceptibility to initiate KA-induced seizures, as predicted in parallel with decreased inhibition. However, we also observed that estradiol has a mitigating effect to reduce seizure severity once seizures have begun. Further investigation showed that estradiol's effect to reduce seizure severity is related to increased release of the anticonvulsant neuropeptide, neuropeptide $\mathrm{Y}$ (NPY).

\section{Materials and Methods}

All procedures were performed in accordance with the National Institutes of Health Guide to the Care and Use of Laboratory Animals and were approved by the Northwestern University Animal Care and Use Committee. All animals were adult female Sprague Dawley rats $(\sim 200 \mathrm{~g}$; Harlan). Rats were ovariectomized under ketamine $(85 \mathrm{mg} / \mathrm{kg}$, i.p. $)$ and xylazine (13 mg/kg, i.p.; both from Lloyd Laboratories) anesthesia using aseptic surgical procedures. Three days after surgery, each rat was given a subcutaneous injection of either $10 \mu \mathrm{g}$ of $17 \beta$-estradiol benzoate (referred to subsequently as estradiol) in $100 \mu \mathrm{l}$ of sesame oil or $100 \mu \mathrm{l}$ of oil vehicle alone as described previously (Rudick and Woolley, 2001; Ledoux and Woolley, 2005). This protocol produces estradiol levels of $\sim 30 \mathrm{pg} / \mathrm{ml}$ measured $24 \mathrm{~h}$ after injection (Woolley and McEwen, 1993), slightly lower than peak proestrus levels (Smith et al., 1975). Except where noted, all chemical reagents were from Sigma.

KA seizure testing. Systemic KA treatment was used to investigate how estradiol affected the latency to initiate behavioral seizures and the severity of seizures. To parallel previous measurements of GABA release, seizure testing was performed $24 \mathrm{~h}$ after estradiol or oil treatment. For each seizure testing session, two rats from different treatment groups were coded so that the experimenter was blind to their treatment condition. Each rat was given an injection ( $15 \mathrm{mg} / \mathrm{kg}$, i.p.) of KA and placed individually in a clean Plexiglas cage. The timing of each episode of stereotyped seizure behavior (Sperk et al., 1985; Woolley, 2000) was recorded over a $2 \mathrm{~h}$ period. One to three testing sessions were conducted per day. KA seizures begin with bouts of immobility and staring, followed by head waving/chewing [stages 1 and 2 as defined by Racine (1972)] and then forelimb clonus (Racine stage 3); in the majority of animals, seizures advance to more severe stages consisting of bouts of rearing/falling (Racine stages 4 and 5) and then tonic-clonic seizure with extreme tonus and vigorous jerking movements. After $2 \mathrm{~h}$ of seizure monitoring, each rat was deeply anesthetized with sodium pentobarbital $(80 \mathrm{mg} / \mathrm{kg}$, i.p.; Virbac $\mathrm{AH}$ ) and perfused with $4 \%$ paraformaldehyde in $0.1 \mathrm{~m}$ phosphate buffer (PB), pH 7.4. The effectiveness of ovariectomy and estradiol treatment was confirmed by visual inspection of the uterus.

Anti-NPY IgG infusion. To investigate the role of NPY in estradiol's effects on KA behavioral seizures, rats were infused intracerebroventricularly with anti-NPY IgG or a control solution before seizure induction, to block the actions of NPY during seizures. Rats were deeply anesthetized with ketamine $(87 \mathrm{mg} / \mathrm{kg}$, i.p. $)$ and xylazine $(13 \mathrm{mg} / \mathrm{kg}$, i.p.; both from Lloyd Laboratories) and placed in a small animal stereotaxic apparatus (David Kopf Instruments). A sterilized Hamilton syringe was used to deliver $5 \mu \mathrm{l}$ of a control solution (sterile saline or rabbit serum) or antiNPY IgG $(10 \mu \mathrm{g} / \mu \mathrm{l}$, rabbit polyclonal; Sigma) (Veliskova and Velisek, $2007)$ into the third ventricle $(-3.0 \mathrm{~mm}$ anteroposterior, $0.1 \mathrm{~mm}$ lateral, $4.5 \mathrm{~mm}$ depth) over a $5 \mathrm{~min}$ period. Animals were treated with $10 \mu \mathrm{g}$ of $17 \beta$-estradiol benzoate or oil vehicle subcutaneously after recovery from stereotaxic surgery. Twenty-four hours after oil or estradiol treatment, each rat was coded and received an injection of KA ( $15 \mathrm{mg} / \mathrm{kg}$, i.p.), and seizure behaviors were monitored for $2 \mathrm{~h}$ as described above. After $2 \mathrm{~h}$, each animal was deeply anesthetized with sodium pentobarbital ( $80 \mathrm{mg} /$ kg, i.p.; Virbac $\mathrm{AH}$ ) and perfused with $4 \%$ paraformaldehyde in $\mathrm{PB}$. Their brains were removed, blocked to contain the hippocampus, and postfixed overnight at $4^{\circ} \mathrm{C}$. Brains were then rinsed, cryoprotected in $30 \%$ sucrose, and sectioned $(40 \mu \mathrm{m})$ through the dorsal hippocampus using a Leica SM2000R freezing microtome. The spread of the anti-NPY antibody was evaluated for each animal by anti-rabbit secondary antibody staining visualized with diaminobenzidine (DAB) using an $A B C$ kit (Vector Laboratories) as described below. Pilot studies confirmed that anti-NPY was detectable throughout the dorsal hippocampus for at least
$48 \mathrm{~h}$ after infusion. There was no difference in seizure behavior between saline- and serum-infused controls. Saline-infused controls showed no secondary antibody staining, whereas serum-infused controls showed a similar pattern as anti-NPY-infused animals, although staining was lighter overall in controls.

Electron microscopic immunocytochemistry. Electron microscopic immunocytochemistry was used in nonseizure animals to localize and quantify NPY immunoreactivity (IR) at the ultrastructural level. Rats were deeply anesthetized with sodium pentobarbital ( $80 \mathrm{mg} / \mathrm{kg}$, i.p.; Virbac $\mathrm{AH}$ ) and perfused with heparinized saline, followed by $3 \%$ paraformaldehyde $/ 0.5 \%$ glutaraldehyde in PB. Brains were removed, blocked to contain the dorsal hippocampus, and postfixed overnight at $4^{\circ} \mathrm{C}$. Blocks were then rinsed and sectioned $(50 \mu \mathrm{m})$ through the dorsal hippocampus using an EMS-4000 oscillating tissue slicer (Electron Microscopy Sciences). Sections were treated with $1 \%$ sodium borohydride and $1 \%$ hydrogen peroxide, followed by a blocking solution containing $3 \%$ bovine serum albumin (BSA), 0.3\% dimethylsulfoxide (DMSO), and 5\% normal serum in Tris-buffered saline (TBS), pH 7.4. After rinsing, sections were incubated in primary antiserum to NPY (rabbit polyclonal, 5.0 $\mu \mathrm{g} / \mathrm{ml}$; Peninsula Laboratories) in 2\% BSA, 0.3\% DMSO, and 1\% normal serum in TBS at $4^{\circ} \mathrm{C}$ for $48 \mathrm{~h}$. Sections were then rinsed and incubated with biotinylated anti-rabbit IgG (1:800; Vector Laboratories) followed by an avidin-biotin horseradish peroxidase complex (1:100; Vector Laboratories) in TBS. NPY-IR was visualized with a DAB reaction. Sections were stained with $1 \%$ osmium tetroxide, flat embedded in Eponate resin (both from Ted Pella), blocked to contain CA1, and mounted for thin sectioning. Short series of ultrathin $(\sim 80 \mathrm{~nm})$ sections were cut on a Reichert Ultracut $S$ ultramicrotome (Leica), collected on formvar-coated slot grids, and stained with 3\% uranyl acetate and 2.66\% Reynold's lead citrate (both from Ted Pella). Controls included omission of primary antiserum and showed no nonspecific staining. Brains were coded before sectioning so that the experimenter was blind to hormone condition during image collection and analysis.

Another group of rats was used for electron microscopic visualization of estrogen receptor- $\alpha(\mathrm{ER} \alpha)$, to investigate whether large dense-core vesicles (LDCVs) contain ER $\alpha$-IR. Procedures were as above, except that tissue was not pretreated with hydrogen peroxide and sections were incubated in primary antiserum to ER $\alpha$ (MC-20 rabbit polyclonal, 0.5 $\mu \mathrm{g} / \mathrm{ml}$; Santa Cruz Biotechnology) followed by nanogold-coupled antirabbit $\operatorname{IgG}$ (1:50) and HQ-silver reagent (both from Nanoprobes), as in the study by Hart et al. (2007). Controls included omission of primary antiserum and showed no nonspecific staining. The MC-20 antiserum used for ER $\alpha$ labeling does not cross-react with ER $\beta$ (Azcoitia et al., 1999) and recognizes a single band of the appropriate size on Western blots from hippocampus (Hart et al., 2007); all staining is eliminated by preadsorption with a blocking peptide (Hart et al., 2001). Because lots of antisera can vary, we verify each lot of MC-20 by Western blot before using it for immunostaining.

Immunostained sections were visualized with a JEOL 1230 transmission electron microscope. For analysis of NPY-IR, four to six $250 \times 500$ $\mu \mathrm{m}$ regions containing the CAl cell body layer and stratum radiatum in each of four to six sections per animal were imaged. Every NPYimmunoreactive structure was digitally captured at 30,000-50,000 $\times$, classified as being contained within a neuronal axon, dendrite, soma, or glial cell, and its area was measured. Serial sections were used to identify structures not readily identifiable in single sections. The total number of images analyzed was 306 (oil) and 368 (estradiol) in the cell body layer and 414 (oil) and 436 (estradiol) in the stratum radiatum. For ER $\alpha$ labeling, 40-60 sections from each of four animals were scanned for boutons containing $\mathrm{ER} \alpha$-immunoreactive LDCVs.

Preparation and stimulation of hippocampal slices. Although our primary interest was in the effects of KA seizures in vivo, an initial experiment was done in vitro to validate the use of double-label immunofluorescence to detect activity-dependent release of NPY from GABAergic varicosities. Acute hippocampal slices were prepared, subjected to various stimulation protocols, and fixed immediately for immunostaining. Slices were prepared as follows. Rats were deeply anesthetized with sodium pentobarbital $(80 \mathrm{mg} / \mathrm{kg}$, i.p.; Virbac $\mathrm{AH})$ and perfused transcardially with ice-cold oxygenated artificial CSF (ACSF) containing (in mM) 
$125 \mathrm{NaCl}, 25 \mathrm{NaHCO}_{3}, 25$ dextrose, $2.5 \mathrm{KCl}, 1.25 \mathrm{NaH}_{2} \mathrm{PO}_{4}, 1 \mathrm{MgCl}_{2}$ and $2 \mathrm{CaCl}_{2}$ (osmolarity, 315; pH 7.4). Rats were decapitated, and their brains were removed rapidly and blocked to contain the dorsal hippocampus. Transverse slices $(200 \mu \mathrm{m})$ were cut into an ice-cold bath of oxygenated ACSF using a Leica VT1000S oscillating tissue slicer. Slices were transferred to a holding chamber, where they were allowed to recover submerged in oxygenated ACSF at $35^{\circ} \mathrm{C}$ for $1 \mathrm{~h}$, and kept at room temperature until stimulation. Slices from each rat were divided into four stimulation groups as described in Results. Each slice was transferred individually to a recording chamber mounted on a Zeiss Axioskop, where it was continuously perfused $(2 \mathrm{ml} / \mathrm{min})$ with warm $\left(33-35^{\circ} \mathrm{C}\right)$ oxygenated ACSF. A glass bipolar stimulating electrode was placed in the CA1 cell body layer. Control slices received no stimulation; low-frequencystimulated slices received $1025 \mathrm{~s}$ trains of $10 \mathrm{~mA}, 1 \mathrm{~ms}$ pulses at $4 \mathrm{~Hz}$; and high-frequency-stimulated slices received $101 \mathrm{~s}$ trains of $10 \mathrm{~mA}, 1 \mathrm{~ms}$ pulses at $100 \mathrm{~Hz}$; an additional group of slices received the same highfrequency stimulation in the presence of $\omega$-conotoxin-MVIIC $(1 \mu \mathrm{M}$; Tocris) and cytochrome $\mathrm{C}(1 \mathrm{mg} / \mathrm{ml})$ to block voltage-gated $\mathrm{Ca}^{2+}$ channels. The interval between stimulus trains was $1 \mathrm{~s}$. Stimulus protocols were created using pCLAMP software (Molecular Devices) and delivered using an A.M.P.I. Iso-Flex stimulus isolator. All slices were left in the recording chamber for the same amount of time, regardless of stimulation group. Immediately after stimulation, each slice was removed from the recording chamber, submersion fixed in $4 \%$ paraformaldehyde in $\mathrm{PB}$, and immunostained for NPY and the $65 \mathrm{kDa}$ form of glutamic acid decarboxylase (GAD65) as described below.

$N P Y+G A D 65$ immunofluorescence. We used double-label immunofluorescence to visualize and quantify NPY-IR contained within GABAergic varicosities; GABAergic varicosities were identified by immunostaining for GAD65, a marker for GABAergic neurons that is concentrated in presynaptic boutons (Kaufman et al., 1991). Tissue was either the acute hippocampal slices stimulated as above or tissue sections from oil- and estradiol-treated rats before or after KA seizures in vivo. To generate tissue sections after in vivo seizures, rats were deeply anesthetized with sodium pentobarbital $(80 \mathrm{mg} / \mathrm{kg}$, i.p.; Virbac $\mathrm{AH})$ and perfused with $4 \%$ paraformaldehyde in PB. Their brains were removed, blocked to contain the hippocampus, and postfixed overnight at $4^{\circ} \mathrm{C}$. Brains were then rinsed, cryoprotected in 30\% sucrose, and sectioned ( 40 $\mu \mathrm{m})$ through the dorsal hippocampus using a Leica SM2000R freezing microtome. Tissue sections and stimulated slices were double labeled with the same rabbit polyclonal NPY antiserum used for immunoelectron microscopy $(5.0 \mu \mathrm{g} / \mathrm{ml}$; Peninsula Laboratories) and a mouse monoclonal antibody to GAD65 (0.5 $\mu \mathrm{g} / \mathrm{ml}$; BD Biosciences). Immunohistochemical processing was the same as for NPY alone, except for visualization with species-specific IgG coupled to Alexa Fluor 488 for NPY and Alexa Fluor 568 for GAD65 (both $2.5 \mu \mathrm{g} / \mathrm{ml}$; Invitrogen). After secondary antibody incubation, tissue was rinsed, mounted onto subbed slides, dehydrated in graded alcohols, cleared with xylene, rehydrated, and coverslipped under Vectashield (Vector Laboratories). Controls included processing tissue with primary antibodies omitted and with each primary antibody alone as in the study by Hart et al. (2007). No nonspecific staining was detected.

Fluorescence image acquisition and analysis. Slices and tissue sections were coded so that the experimenter was blind to the treatment group during all imaging and analysis. Tissue was imaged using a PerkinElmer Ultraview spinning disc laser confocal microscope with a $100 \times$ oilimmersion objective. In slices, the stimulation site was identified by a small hole left by the stimulating electrode. For each slice, two stacks of 11 images $\left(81 \times 61 \times 0.2 \mu \mathrm{m}\right.$, for a total stack volume of $\left.10,870 \mu \mathrm{m}^{3}\right)$, one on each side adjacent to the stimulation site, were collected and imported into Volocity software (Improvision); each image stack contained the cell body layer and proximal stratum radiatum. Minimum $\left(0.01 \mu \mathrm{m}^{3}\right)$ and maximum $\left(3.0 \mathrm{\mu m}^{3}\right)$ size thresholds for identification of NPYimmunoreactive puncta were set using the classifier function in Volocity. The number of individual NPY-immunoreactive puncta colocalized with GAD65-IR (NPY+GAD65-immunoreactive puncta) was expressed per cubed micrometer of GAD65. For quantification of NPY staining in tissue sections before or after in vivo seizures, three stacks of 11 images $\left(81 \times 61 \times 0.2 \mu \mathrm{m}\right.$, for a total stack volume $\left.10,870 \mu \mathrm{m}^{3}\right)$ were collected from each hemisphere in both the CA1 cell body layer and stratum radiatum in each of three sections per brain, for a total of 18 image stacks per subregion, per brain. Sections were equally spaced from bregma -2.80 to $-3.30 \mathrm{~mm}$. Minimum $\left(0.01 \mu \mathrm{m}^{3}\right)$ and maximum $\left(3.0 \mu \mathrm{m}^{3}\right)$ size thresholds for NPY-immunoreactive puncta were the same as for the analysis in slices. The average sum intensity, a measure that combines size and brightness, and number of individual NPY+GAD65immunoreactive puncta per image stack were quantified with Volocity. The greater number of image stacks per animal that could be collected from tissue sections allowed for quantification of NPY+GAD65immunoreactive puncta per stack, without normalization to GAD65 volume in the stack. Nevertheless, as a control, the average intensity and volume of GAD65-IR were also quantified. The volume of GAD65-IR per stack was measured rather than the varicosity number because the fiberlike staining that often connected varicosities precluded automated identification of individual varicosities. It is important to note that in all experiments, measurements of NPY + GAD65-IR reflect NPY labeling; GAD65 labeling was used only to identify NPY puncta present in GABAergic varicosities as opposed to other structures.

Cell fractionation by sucrose density gradient centrifugation. Cell fractionation was used as one of two approaches to investigate the subcellular distribution of $\mathrm{ER} \alpha$ in the hippocampus; immunogold labeling for $\mathrm{ER} \alpha$ described above was the other approach. Rats were deeply anesthetized with sodium pentobarbital $(80 \mathrm{mg} / \mathrm{kg}$, i.p.; Virbac $\mathrm{AH})$ and perfused transcardially with ice-cold homogenization buffer containing (in mM) 5 HEPES-KOH, pH 7.2, 320 sucrose, 5 EDTA, 50 NaF, 10 Na pyrophosphate, $20 \mathrm{Na}$ glycerophosphate, $1 \mathrm{Na}$ orthovanadate, 0.1 PMSF, $1 \mu \mathrm{g} / \mathrm{ml}$ leupeptin, and $1 \mu \mathrm{g} / \mathrm{ml}$ aprotinin. Rats were decapitated, and all subsequent steps were performed on ice or at $4^{\circ} \mathrm{C}$. Brains were removed, and hippocampi were dissected out. Tissue from four rats was pooled and homogenized in $1 \mathrm{ml}$ of homogenization buffer. The homogenate was centrifuged at $1000 \times g$ for 15 min to remove unbroken cells and nuclei. An aliquot of the resulting postnuclear supernatant (PNS) was saved for Western blot analysis. The remaining PNS was loaded on top of a linear sucrose gradient (0.6-1.8 $\mathrm{m}$ sucrose, made in $5 \mathrm{~mm}$ HEPES-KOH, pH 7.2, with $0.1 \mathrm{~mm}$ PMSF, $1 \mu \mathrm{g} / \mathrm{ml}$ leupeptin, and $1 \mu \mathrm{g} / \mathrm{ml}$ aprotinin) and centrifuged at $110,000 \times g$ for $12 \mathrm{~h}$. Twelve fractions were then collected from the top of the gradient and stored at $-80^{\circ} \mathrm{C}$.

Protein concentration in each sample was determined using the Bradford protein assay (Bio-Rad). Samples containing equal total protein were separated on a $10 \%$ SDS-PAGE gel and transferred to a polyvinylidene difluoride membrane (Bio-Rad). The membrane was blocked with $5 \%$ nonfat milk and incubated with an antibody against ER $\alpha$ (MC-20, 1:2000; Santa Cruz Biotechnology), CAPS-1 (1:500; BD Biosciences), or synaptophysin (MAB5258, 1:2,500,000; Chemicon), followed by horseradish peroxidase-coupled anti-rabbit $(1: 1000)$ or anti-mouse (1:2000) IgG (Vector Laboratories). Bands were visualized with enhanced chemiluminescence (ECL Plus; GE Healthcare) and quantified using Image Pro Plus software (Media Cybernetics).

Statistics. SPSS software was used to perform repeated-measures or two-way ANOVA, post hoc tests, or unpaired, two-tailed $t$ tests, as appropriate. The two-tailed Fisher's exact test was used to compare the proportion of animals reaching the rearing/falling stage of seizure behavior, and the Wilcoxon-Mann-Whitney test was used to compare the distributions of means in immunoelectron microscopic analysis of NPY-IR. All data in bar graphs are presented as mean \pm SEM.

\section{Results}

Estradiol simultaneously increases seizure susceptibility and decreases seizure severity

We began by asking whether the same estradiol treatment that decreases GABA release in the hippocampus (Rudick and Woolley, 2001; Rudick et al., 2003; Ledoux and Woolley, 2005) also affects hippocampus-dependent behavioral seizures. Ovariectomized adult female rats were treated either with $17 \beta$-estradiol (the most potent estrogen in rats) or oil vehicle. Twenty-four hours later, each rat was given an injection of $\mathrm{KA}$, and its behavior was monitored for $2 \mathrm{~h}$. Within a $2 \mathrm{~h}$ period, rats typically cycle 

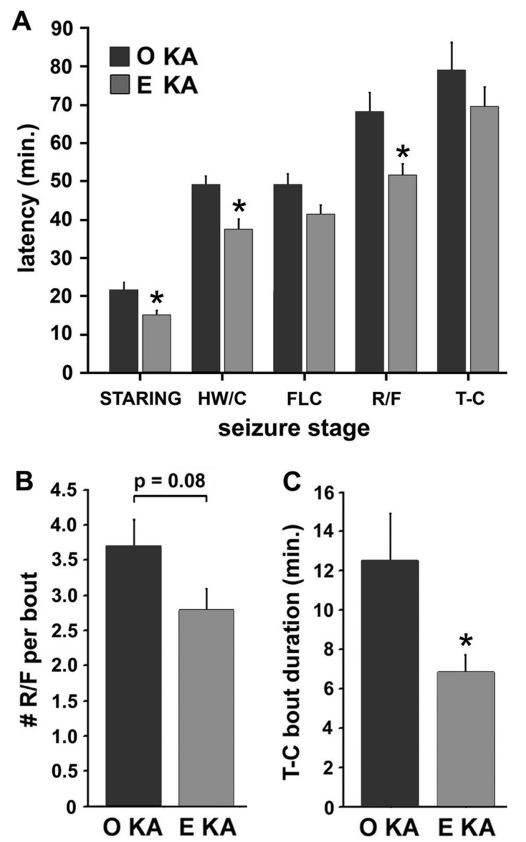

Figure 1. Estradiol increases susceptibility to KA seizures but also decreases seizure severity. $A$, Mean \pm SEM latencies to KA-induced behavioral seizures. Latencies were significantly lower in estradiol-treated ( $n=19)$ compared with oil-treated $(n=18)$ rats $(p<0.05)$. Latencies to staring, head waving/chewing, and rearing/falling were significantly decreased ( $p$ values $<0.05$ ); latency to forelimb clonus and tonic-clonic seizures also were reduced but did not reach statistical significance. $\boldsymbol{B}$, Mean \pm SEM number of rearing/falling events per bout in the subset of each group that reached this seizure stage. The number of rearing/falling per bout tended to be lower in estradiol-treated $(n=13)$ than oil-treated $(n=17 ; p=0.08)$ rats. $C$, Mean \pm SEM duration of tonic-clonic seizures in the subset of each group that reached this seizure stage. The duration of tonic-clonic seizures was significantly lower in estradiol-treated $(n=12)$ than oil-treated $(n=13 ; p<0.05)$ rats. E KA, Estradiol-treated, KA-treated; $0 \mathrm{KA}$, oil-treated, KA-treated; HW/C, head waving/chewing; R/F, rearing/falling; $F L C$, forelimb clonus; $\mathrm{T}-\mathrm{C}$, tonic- clonic seizures.

through multiple bouts of seizure behavior interspersed with seizure-free periods, and successive bouts of seizure incorporate more severe stages. Latency to the first observation of each seizure behavior is a common measure of seizure susceptibility. Importantly, electrophysiological, metabolic mapping, and immediateearly gene expression studies indicate that KA seizures begin in the hippocampus (Lothman and Collins, 1981; Willoughby et al., 1997; Zeng et al., 2007). As such, factors that increase hippocampal seizure susceptibility are expected to decrease latency to the earliest stages of seizure behavior, and possibly subsequent seizure stages as well.

Thirty-seven of 42 rats that received injections of KA had behavioral seizures, and the latencies to seizure stages were significantly lower in the estradiol-treated $(n=19)$ than oil-treated $(n=18)$ group (repeated-measures ANOVA; $F_{(1,23)}=5.50 ; p<$ 0.05) (Fig. $1 A$ ). Estradiol significantly decreased latencies to staring (by 29\%), head waving/chewing (by 23\%), and rearing/falling (by $25 \%$; $p$ values $<0.05$ ); mean latencies to forelimb clonus and tonic-clonic seizures also were lower but did not reach statistical significance ( $p=0.09$ and 0.30 , respectively). Thus, estradiol increased susceptibility to seizure initiation. Interestingly, however, although seizures occurred sooner in estradiol-treated rats, fewer estradiol- than oil-treated rats reached the more severe seizure stages, particularly rearing/falling. Of the 18 oil-treated rats that had seizures, 17 of them (94\%) reached the rearing/ falling stage, whereas only 13 of $19(68 \%)$ estradiol-treated rats reached this stage (two-tailed Fisher's exact test, $p<0.05$; data not shown). This was surprising, because it indicated a seizure mitigating, rather than seizure promoting, effect. Twelve of 19 $(63 \%)$ estradiol-treated and 13 of $18(72 \%)$ oil-treated rats reached the tonic-clonic seizure stage.

Next, we asked how estradiol affects the duration of rearing/ falling and tonic-clonic seizure bouts, as an indication of seizure severity. We found that both seizure types were shorter in the estradiol group. Within each bout of rearing/falling, rats rear and fall repeatedly, and the number of repetitions is related to the length of that bout. Comparison of rearing/falling events per bout in oil-treated $(n=17)$ and estradiol-treated $(n=13)$ rats showed a trend toward fewer events per bout in the estradiol group (unpaired, two-tailed $t$ test, $p=0.08$ ) (Fig. $1 B$ ). Analysis of tonic-clonic seizures showed clearly that estradiol shortened seizure duration. The average length of each tonic-clonic seizure was only half as long in the estradiol $(n=12)$ compared with the oil $(n=13)$ group (unpaired, two-tailed $t$ test, $p<0.05)$ (Fig. $1 C)$. Thus, estradiol simultaneously increased seizure susceptibility, as evidenced by decreased latencies to seizure initiation, but also shortened the duration of advanced KA seizures, indicating a reduction in seizure severity.

That the progression of KA seizures and their severity were suppressed in estradiol-treated animals led us to consider the possibility that, in addition to decreasing GABAergic inhibition, estradiol might potentiate a factor that limits the severity of seizures once they have begun. One candidate for such a factor is NPY. NPY is found in a subset of inhibitory neurons in the hippocampus (Haas et al., 1987; Milner and Veznedaroglu, 1992; Freund and Buzsáki, 1996), is released in the hippocampus during KA seizures (Husum et al., 1998), and is implicated in terminating the advanced stages of KA seizure behavior with little effect on seizure latency (Baraban et al., 1997; Weinshenker et al., 2001; Lin et al., 2006).

\section{Immunoneutralization of NPY blocks the estradiol-induced decrease in seizure severity}

If the estradiol-induced decrease in seizure severity depends on NPY, then blocking NPY during seizures should eliminate the difference in seizure duration between estradiol-treated and control animals. We used immunoneutralization to block NPY, as opposed to NPY receptor antagonists, because immunoneutralization makes no assumptions about which NPY receptor(s) is involved in terminating seizures (Woldbye et al., 1997; El Bahh et al., 2005) and allows for post hoc confirmation of anti-NPY in the hippocampus for each animal.

Forty-three animals were infused intracerebroventricularly with either anti-NPY IgG or a control solution (Fig. 2A) (Veliskova and Velisek, 2007) and treated with oil or estradiol. Twentyfour hours later, each animal was given an injection of KA, and its seizure behavior was monitored for $2 \mathrm{~h}$. Of the 43 infused animals, 26 (60\%) progressed at least to the rearing/falling stage and were included in analysis of seizure severity. The distribution among groups was as follows: control-infused oil $(n=6)$ or estradiol $(n=8)$ treated; and anti-NPY-infused oil $(n=5)$ or estradiol $(n=7)$ treated. After seizure testing, each animal was perfused, and its brain was processed for visualization of antiNPY (Fig. 2B).

Analysis of seizures in infused animals showed that the estradiol-induced decrease in seizure severity depends on NPY. As expected, estradiol decreased the duration of severe seizures in control-infused animals. Furthermore, anti-NPY infusion increased seizure duration to a much greater extent in estradioltreated animals, eliminating the difference between hormone 
A

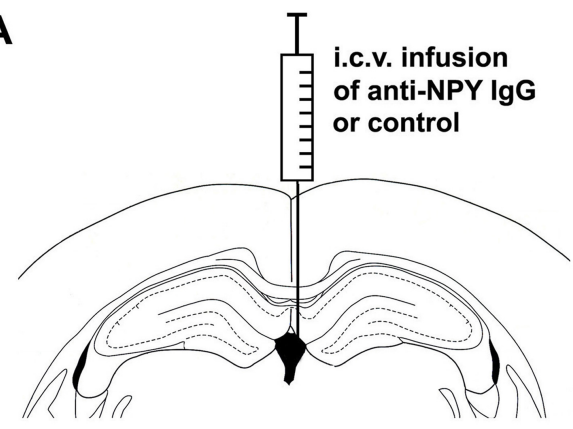

B
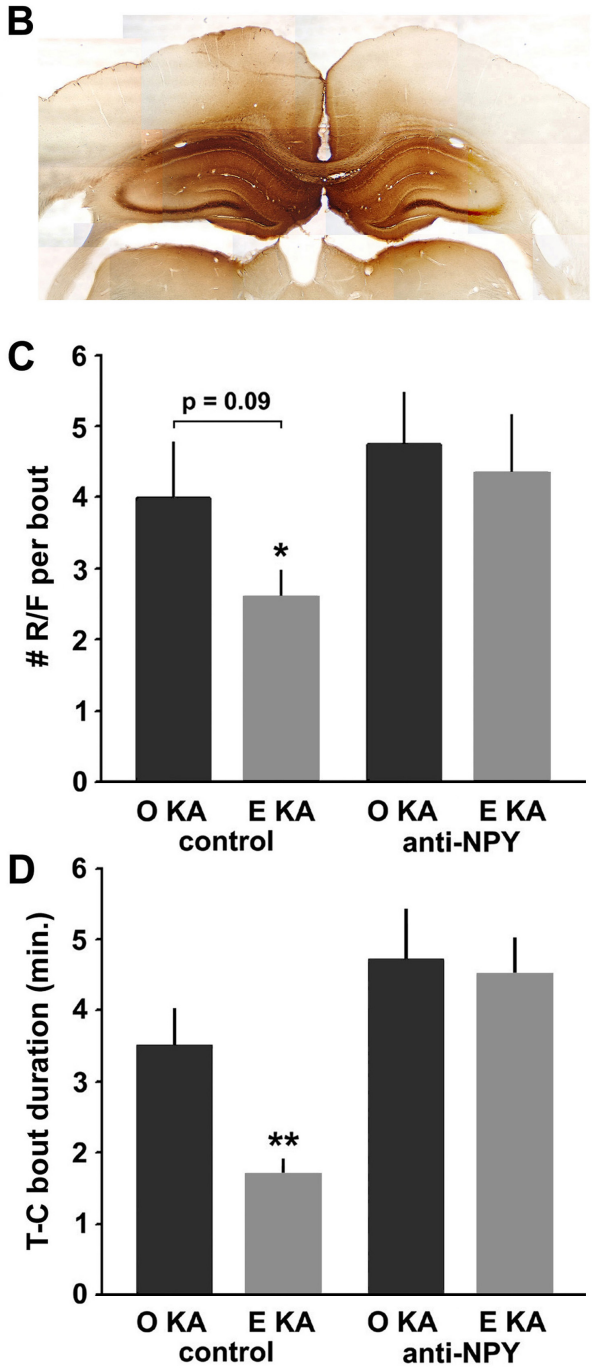

Figure 2. Immunoneutralization of NPY eliminates the estradiol-induced decrease in seizure severity. $\boldsymbol{A}$, Schematic showing anti-NPY IgG or control infusion intracerebroventricularly (i.c.v.). $\boldsymbol{B}$, Photomicrograph montage of a representative section showing anti-NPY staining in an animal from this experiment; infused anti-NPY was restricted to the hippocampus and immediately surrounding areas. C, Mean \pm SEM number of rearing/falling (R/F) events per bout in oil-treated $(n=6)$ and estradiol-treated $(n=8)$ control-infused animals and oil-treated $(n=5)$ and estradiol-treated ( $n=$ 7) anti-NPY-infused animals. Estradiol tended to decrease the number of R/F events per bout in control-infused animals ( $p=0.09$ ), and the number of $\mathrm{R} / \mathrm{F}$ events per bout was significantly increased by anti-NPY infusion in estradiol-treated animals ( ${ }^{*} p<0.05$, significant difference from both anti-NPY-infused groups). Anti-NPY infused groups were not different. $\boldsymbol{D}$, Mean \pm SEM duration of tonic-clonic ( $\mathrm{T}-\mathrm{C})$ seizures in the same animals as in $C$. Estradiol significantly decreased the duration of T-C seizures in control-infused animals $(p<0.05)$, and $\mathrm{T}-\mathrm{C}$ seizure duration was significantly increased by anti-NPY infusion in estradiol-treated animals $\left({ }^{* *} p<0.01\right.$, significant difference from both anti-NPY-infused groups). Anti-NPY-infused groups were not different. $0 \mathrm{KA}$ control, Oil-treated control-infused; EKA control, estradiol-treated control-infused; 0 KA anti-NPY, oil-treated anti-NPYinfused; EKA anti-NPY, estradiol-treated anti-NPY-infused. groups. For rearing/falling seizures, the number of events per bout was significantly different overall (two-way ANOVA; $F_{(3,22)}$ $=3.12 ; p<0.05)$ (Fig. $2 C$ ). Estradiol decreased events per bout in control-infused animals although, as in the initial experiment (Fig. $1 B)$, this did not reach statistical significance $(p=0.09)$. Importantly, however, the number of events per bout was significantly increased by anti-NPY specifically in estradiol-treated animals $(p<0.05)$. Anti-NPY did not significantly increase events per bout in oil-treated animals, and there was no difference between the anti-NPY-infused estradiol- or oil-treated groups ( $p$ values $>0.10$ ).

The results were similar for tonic-clonic seizures. All the animals that reached rearing/falling also progressed to tonic-clonic seizures. As for rearing/falling, we found a significant overall effect on tonic-clonic seizure duration (two-way ANOVA; $F_{(3,21)}$ $=7.14 ; p<0.01)($ Fig. $2 D)$. As in our initial experiment (Fig. $1 C)$, tonic-clonic seizures lasted only half as long in estradiol- compared with oil-treated controls $(p<0.05)$. Additionally, antiNPY infusion increased tonic-clonic seizure duration in estradiol-treated animals $(p<0.01)$, leading to no difference between anti-NPY-infused oil- and estradiol-treated animals ( $p$ values $>0.10$ ). Thus, for both types of severe KA seizures, antiNPY infusion blocked the estradiol-induced decrease in seizure severity and eliminated the difference between oil- and estradioltreated animals. Because infused anti-NPY was confined primarily to the hippocampus, these results provide strong evidence that hippocampal NPY is primarily responsible for estradiol's effect to decrease seizure severity.

In contrast to its effects on seizure severity and consistent with most studies of NPY effects on KA seizures, we found no evidence that anti-NPY infusion affected the latency to any seizure stage ( $p$ values $>0.10$; data not shown). Also, although it does not affect interpretation of our results, we note that the durations of tonicclonic seizures in this experiment were unexpectedly lower than in the first experiment. The proportion of rats that progressed to the advanced stages of KA seizures was also slightly lower. These differences may be related to hippocampal damage caused by infusions and/or to use of a different (older) lot of KA in the first experiment versus one obtained recently in the second experiment.

\section{Estradiol increases the NPY content of inhibitory boutons}

That the estradiol-induced decrease in seizure severity depends on NPY raises the question of how estradiol regulates NPY to decrease seizure severity. As noted previously, NPY is found in a subset of GABAergic neurons in the hippocampus. In vitro electrophysiological studies in hippocampus indicate that NPY exerts its anticonvulsant effects, at least in part, through suppression of excitatory synaptic transmission (Colmers et al., 1987; Haas et al., 1987). Furthermore, the same duration of estradiol treatment used here $(24 \mathrm{~h})$ has been shown to increase the number of NPYimmunoreactive cells in the CA1 region of the hippocampus (Nakamura and McEwen, 2005), suggesting that it may increase NPY levels. Therefore, we next asked whether estradiol increases the pool of potentially releasable NPY in hippocampal neurons.

We used electron microscopic immunocytochemistry to visualize NPY-IR in the CA1 stratum radiatum and cell body layer of oil- and estradiol-treated rats. Consistent with previous observations (Aoki and Pickel, 1989; Milner and Veznedaroglu, 1992), we observed NPY-IR primarily in a subset of axonal boutons that form symmetric (i.e., inhibitory) synapses with dendritic shafts (Fig. $3 A, B$ ) and cell bodies, as well as in axons, dendrites, and somatic organelles (e.g., endoplasmic reticulum and Golgi). In many cases, NPY-IR was associated with LDCVs, but, as others 
have reported (Milner and Veznedaroglu, 1992), it was also found in boutons that did not appear to contain LDCVs. Inhibitory boutons containing NPY-IR were often observed near boutons that formed asymmetric (i.e., excitatory) synapses with dendritic spines (Fig. $3 A, B$ ), consistent with the proposed role of NPY released from inhibitory boutons to suppress glutamate release at nearby excitatory synapses.

We measured the area of NPY-IR as an initial indication of the amount of NPY associated with each labeled structure. Analysis of 720 labeled structures in oiltreated rats and 804 labeled structures in estradiol-treated rats showed that the areas of NPY-IR in inhibitory boutons were significantly larger in the estradiol-treated than the oil-treated group, both in the cell body layer (Wilcoxon-Mann-Whitney test, $p<0.01$ ) (Fig. 3C) and stratum radiatum $(p<0.05)$ (Fig. 3D). Interestingly, this effect was specific to NPY-IR in inhibitory boutons because no differences were detected for NPY-IR in any other structure ( $p$ values $>0.10$ ) (Fig. $3 E, F)$. Insofar as area of NPY-IR is related to the amount of NPY, larger areas of NPY-IR suggest greater NPY content of inhibitory boutons in estradiol-treated rats, which might, in turn, provide more NPY to be released during seizures.

\section{An approach to detect activity- \\ dependent release of NPY}

To investigate NPY on a larger scale than is feasible with immunoelectron microscopy, we used double-label immunofluorescence for NPY and GAD65, a marker for GABAergic boutons (Kaufman et al., 1991). GAD65 immunostaining revealed numerous varicosities, a subset of which contained punctate NPY-IR (Fig. 4A, 5A$D)$. These NPY + GAD65-immunoreactive puncta likely correspond to NPY contained within inhibitory boutons.

NPY, like other neuropeptides, is released by bursts of highfrequency firing (Bartfai et al., 1988). We used extracellular stimulation in acute hippocampal slices to determine whether NPY+GAD65 immunofluorescence could be used to detect activity-dependent release of NPY. Slices were prepared from adult female rats and distributed across four groups: nonstimulated ( $n=12$ slices), low-frequency stimulated (10 $25 \mathrm{~s}$ trains at 4 $\mathrm{Hz} ; n=10)$, high-frequency stimulated $(101 \mathrm{~s}$ trains at $100 \mathrm{~Hz}$; $n=14)$, and high-frequency stimulated in the presence of $\omega$-conotoxin MVIIC to block $\mathrm{Ca}^{2+}$-dependent release $(n=8)$. Slices were fixed and immunostained immediately after stimulation and imaged with confocal microscopy.

Counting the number of NPY-immunoreactive puncta colocalized with GAD65 showed that high-frequency stimulation decreased the number of NPY+GAD65-immunoreactive puncta. Results were the same in both the cell body layer and stratum radiatum, so the data were combined $\left(\mathrm{ANOVA} ; F_{(3,40)}=4.84\right.$;
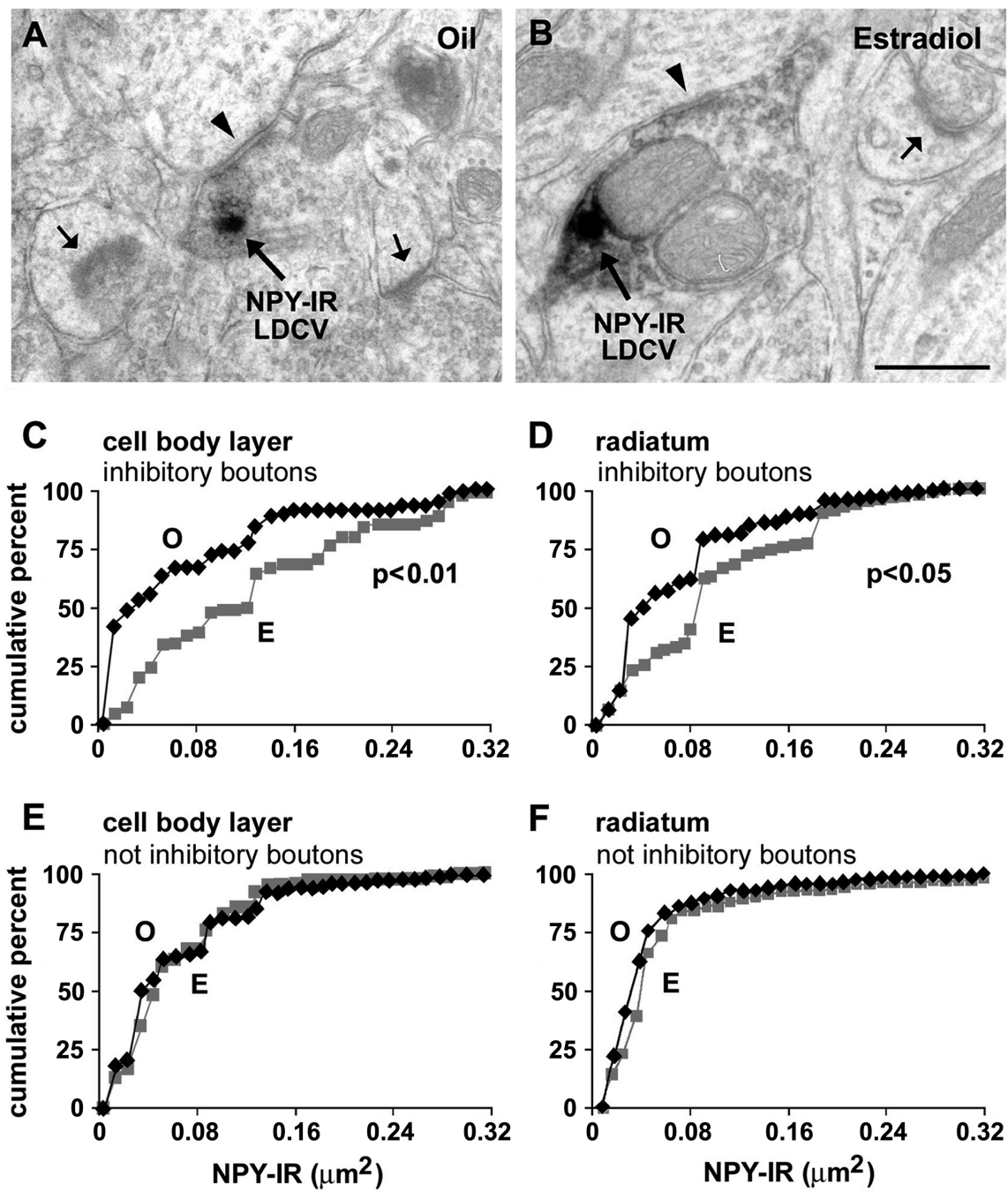

Figure 3. Estradiol increases the area of NPY-IR specifically in inhibitory boutons. $\boldsymbol{A}, \boldsymbol{B}$, Electron micrographs showing boutons that contain NPY-immunoreactive putative LDCVs in the stratum radiatum of an oil $(\boldsymbol{A})$ and estradiol $(\boldsymbol{B})$ rat. NPY-IR-containing (than oil $(0)$ animals in both the cell body layer $(\boldsymbol{C} ; p<0.01)$ and radiatum $(\boldsymbol{D} ; p<0.05)$, whereas there is no difference in the areas of NPY-IR in structures other than inhibitory boutons in either the cell body layer $(\boldsymbol{E})$ or radiatum $(\boldsymbol{F})$.

$p<0.01$ ) (Fig. 4B). The number of puncta was lowest in the high-frequency group compared with nonstimulated, lowfrequency stimulated ( $p$ values $<0.05$ ) or high-frequency stimulated in the presence of $\omega$-conotoxin MVIIC $(p=0.06)$. No parameter of GAD65-IR was affected by stimulation ( $p$ values $>0.10$ ). That high-frequency stimulation decreased the number of detectable NPY+GAD65-immunoreactive puncta suggests that sufficient NPY was released by stimulation to drop levels below detection in a large fraction of boutons. Elimination of this effect by $\omega$-conotoxin MVIIC, which blocks both N- and P/Qtype $\mathrm{Ca}^{2+}$ channels, confirmed that the stimulation-induced decrease in NPY + GAD65-immunoreactive puncta depended on $\mathrm{Ca}^{2+}$ influx, consistent with activity-dependent release of NPY.

Seizures decrease the NPY content of inhibitory boutons Stimulation in hippocampal slices validated the use of $\mathrm{NPY}+$ GAD65 immunofluorescence to detect activitydependent release of NPY from inhibitory boutons. We then used the same approach to investigate how KA seizures in vivo affect 

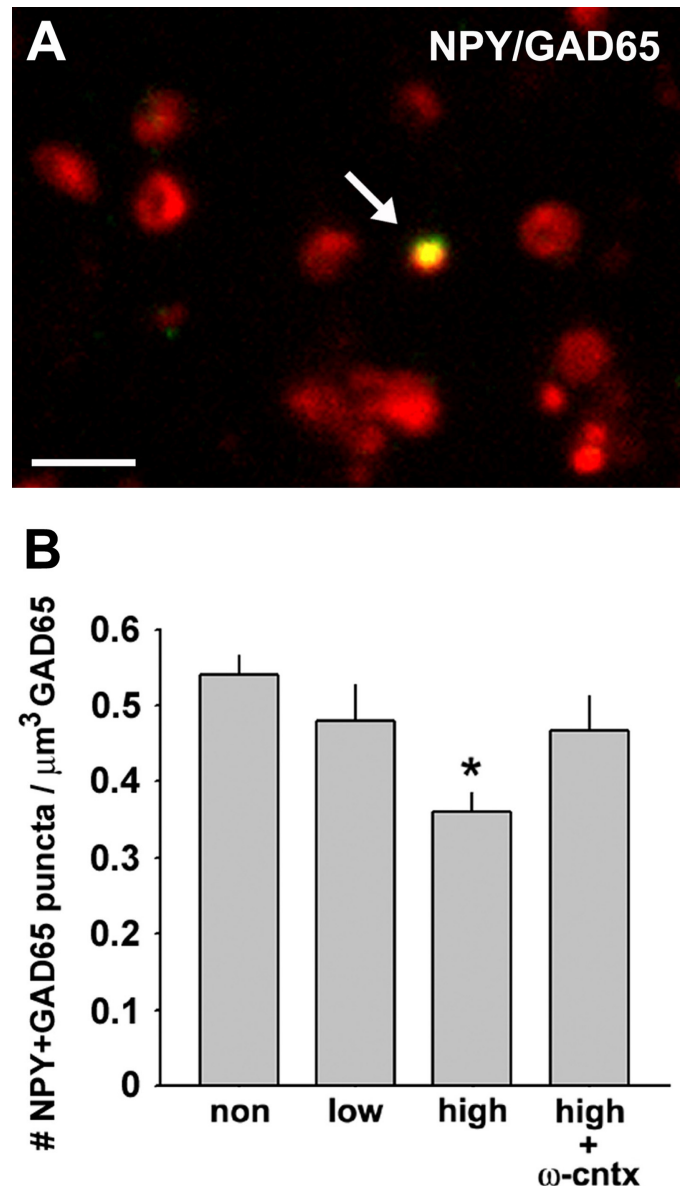

Figure 4. Use of NPY + GAD65 immunofluorescence to detect activity-dependent release of NPY from inhibitory varicosities. $\boldsymbol{A}$, Double-label immunofluorescence for NPY (green) and GAD65 (red) after stimulation in a hippocampal slice. NPY + GAD65 puncta (yellow; arrow) were analyzed. Scale bar, $1 \mu \mathrm{m}$. $\boldsymbol{B}$, The number of NPY + GAD65 puncta per cubed micrometer of GAD65 was lower in high-frequency-stimulated slices $(n=14)$ compared with nonstimulated (non; $n=12 ; p<0.05$ ), low-frequency stimulated (low; $n=10 ; p<0.05$ ), or highfrequency stimulated in the presence of $\omega$-conotoxin MVIIC (high $+\omega$-cntx) to block $\mathrm{Ca}^{2+}$ dependent release $(n=8 ; p=0.06)$. ${ }^{*}$ indicates a significant difference from non and low groups. The frequency-dependent loss of NPY-immunoreactive puncta and block by $\omega$-conotoxin MVIIC are consistent with activity-dependent release of NPY.

NPY in inhibitory boutons in oil- and estradiol-treated rats. We compared NPY + GAD65-IR in four groups of animals: oil- and estradiol-treated control rats $(n=6$ each) and oil- and estradioltreated rats that were given KA seizures $(n=7$ each). Seizure behavior was monitored for $2 \mathrm{~h}$ after KA injection, followed immediately by perfusion of all rats for immunostaining and confocal microscopy. Similar to staining in slices, NPY + GAD65 immunostaining in tissue sections revealed numerous varicosities in the cell body layer and stratum radiatum, a subset of which contained punctate NPY-IR (Fig. 5A-D).

We first asked whether the estradiol-induced increase in NPY-IR in inhibitory boutons seen by immunoelectron microscopy (Fig. 3) was apparent in NPY + GAD65-labeled tissue. We quantified the sum intensity, a measure that combines size and staining intensity, of individual NPY-immunoreactive puncta contained within GAD65-immunoreactive varicosities and found significant differences in the cell body layer (two-way ANOVA; $\left.F_{(3,22)}=3.35 ; p<0.05\right)($ Fig. $5 E$ ) and stratum radiatum (two-way ANOVA; $F_{(3,22)}=4.64 ; p<0.05$ ) (Fig. $5 F$ ). Consistent with results from electron microscopy, the sum intensity of this
NPY labeling in nonseizure rats was significantly increased by estradiol in both the cell body layer and radiatum ( $p$ values $<0.05)$. Next, we asked how KA seizures affected the sum intensity of NPY-IR colocalized with GAD65 and found that this measure was significantly decreased by seizures in both oil- and estradiol-treated rats ( $p$ values $<0.05)$. The lower sum intensity of NPY-immunoreactive puncta in KA-treated groups, indicating smaller or less intense NPY staining, suggests that some NPY was released from inhibitory boutons during seizures. To confirm that these differences were specific to NPY-IR, we measured the volume and intensity of GAD65-IR in the same image stacks and found no significant differences ( $p$ values $>0.10$; data not shown).

\section{Estradiol potentiates the seizure-related decrease in NPY content of inhibitory boutons}

Further analysis indicated that the effect of seizures to reduce NPY-IR was greater in the estradiol-treated rats. Using the same image stacks as above, we counted the total number of NPY+GAD65-immunoreactive puncta in each stack; initially, we made these measurements regardless of the seizure stages reached by each KA-treated rat. This analysis indicated a statistical trend toward an effect of seizures to decrease NPY + GAD65immunoreactive puncta number differentially in oil- versus estradiol-treated rats, with a greater effect in the estradiol group (two-way ANOVA; $F_{(3,22)}=2.23 ; p=0.11$; hormone $\times$ seizure interaction, $p=0.09$ ) (Fig. $6 A$ ). Then, based on previous studies suggesting that NPY is released preferentially during more advanced seizure stages (Baraban et al., 1997; Weinshenker et al., 2001), we separated the KA-treated groups into rats that did or did not progress to severe seizure stages. Repeating the puncta count analysis on these groups revealed a dramatic effect of rearing/falling and tonic-clonic seizures to decrease NPY+GAD65immunoreactive puncta number specifically in estradiol-treated rats. Results were the same for the cell body layer and stratum radiatum.

Recall that, in the first experiment, fewer estradiol- than oiltreated rats reached the more severe seizure stages. Similarly, in the current experiment, all seven oil-treated rats reached the rearing/falling stage, whereas only four of seven estradiol-treated rats progressed to rearing/falling. Comparing the number of NPY + GAD65-immunoreactive puncta in oil-treated rats to that in estradiol-treated rats that did or did not reach the rearing/ falling stage revealed that the number of puncta was decreased by more than half in the estradiol-treated rats that experienced rearing/falling seizures (ANOVA; $F_{(2,11)}=5.96 ; p<0.05$ ) (Fig. $6 B$ ). In contrast, oil-treated animals that experienced rearing/falling seizures were not different from estradiol-treated rats that did not $(p>0.10)$ (Fig. 6B). Similar results were found with tonicclonic seizures. Three of seven oil-treated and four of seven estradiol-treated rats progressed to tonic-clonic seizures. Only in estradiol-treated rats, however, did tonic-clonic seizures decrease NPY + GAD65-immunoreactive puncta number, again by more than half (ANOVA; $F_{(3,10)}=4.13 ; p<0.05$ ) (Fig. 6C). Tonic-clonic seizures did not affect puncta number in the oil group $(p>0.10)$ (Fig. 6C). Interestingly, two of the oil-treated rats in this experiment had been seizing for a prolonged period at the $2 \mathrm{~h}$ time point after KA, one for $30 \mathrm{~min}$ and the other for 32 min; these rats likely were in status epilepticus. Despite seizure at the time of terminal anesthesia, however, neither showed the decrease in NPY + GAD65-immunoreactive puncta number that was evident in estradiol-treated rats that had severe seizures. This 
ancillary observation supports the contention that seizure-related NPY release is increased by estradiol.

To confirm that the seizure-related loss of immunostaining was specific for NPY, we measured the intensity and volume of GAD65-IR in the same image stacks and found no effect of rearing/falling or tonicclonic seizures $(p$ values $>0.10)$. Thus, specifically in the estradiol group, experiencing the most advanced KA seizure stages was associated with a loss of NPYimmunoreactive puncta from inhibitory varicosities. Given that this loss of NPY-IR likely reflects activity-dependent release of NPY (Fig. 4), that such a decrease occurred only in estradiol-treated rats indicates that NPY release was greater in this group. Together with the immunoneutralization experiment, these data indicate that the estradiol-induced decrease in KA seizure severity is attributable to greater seizureinduced release of NPY.

\section{$\mathrm{ER} \alpha$ is found on LDCVs}

How might estradiol facilitate NPY release? In a previous study (Hart et al., 2007), we found that a portion of small, putative synaptic vesicles in inhibitory boutons is immunoreactive for the $\alpha$ form of the estrogen receptor $(\mathrm{ER} \alpha)$ and that estradiol treatment mobilized specifically these ER $\alpha$-immunoreactive vesicles closer to potential release sites. This raises the intriguing possibility that estradiol can facilitate vesicle release through direct action on ER $\alpha$-containing vesicles. Thus, if LD$\mathrm{CV}$ s also contain $\mathrm{ER} \alpha$, this would suggest that estradiol facilitates NPY release by acting directly on LDCVs. We used two approaches to investigate this, cell fractionation and immunoelectron microscopy, both of which showed that LDCVs contain $\mathrm{ER} \alpha$.

For cell fractionation studies, we prepared PNS from adult female rat hippocampus, centrifuged it through a linear sucrose density gradient to equilibrium, and collected 12 fractions starting from the top of the gradient. This approach has been well characterized in pituitary tissue (Navone et al., 1989; WalchSolimena et al., 1993) and also used to separate synaptic vesicles from LDCVs in brain (Saegusa et al., 2002). In previous studies, three regions of the gradient can be resolved: the lightest fractions near the top contain soluble proteins, the middle fractions $(\sim 1.0$ $\mathrm{M})$ are enriched in synaptic vesicles, and the densest fractions near the bottom $(\sim 1.6 \mathrm{M})$ contain LDCVs.

We probed Western blots of the PNS and all 12 sucrose density fractions for $\mathrm{ER} \alpha$ and two different vesicle markers, $\mathrm{Ca}^{2+}$. dependent activator protein for secretion 1 (CAPS1) and synaptophysin (Fig. 7A, top). CAPS1 is primarily a soluble protein (Berwin et al., 1998; Speidel et al., 2003), but a fraction of CAPS1 is associated with LDCV membranes (Berwin et al., 1998) where it regulates LDCV exocytosis (Tandon et al., 1998). Synaptophysin, in contrast, is primarily associated with synaptic vesicles but is also present on LDCVs (Berwin et al., 1998). For each analyzed protein, band optical density was quantified on films obtained from three separate Western blot analyses and expressed as a percentage of the summed optical density of all 12 fractions for the given protein (Fig. $7 A$, bottom). This allowed comparison of the distribution of each protein across the gradient.

As described for pituitary fractions (Walch-Solimena et al., 1993), three regions of the sucrose gradient were apparent: the lightest fractions likely contained soluble proteins, as indicated by the major peak of CAPS1 in fractions 3-5; the middle fractions contained synaptic vesicles, as indicated by the main synaptophysin peak detected in fractions 6 and 7; and the bottom fractions likely contained LDCVs, as indicated by the presence of both CAPS1 and synaptophysin in fraction 11. Remarkably, we found the greatest concentration of ER $\alpha$ in the LDCV fractions 10 and 11, although some $\operatorname{ER} \alpha$ was also detected in fractions 7-9. The presence of ER $\alpha$ in the middle fractions containing synaptic vesicles was expected from our previous studies (Hart et al., 2007).

The cell fractionation analysis strongly suggested that ER $\alpha$ 

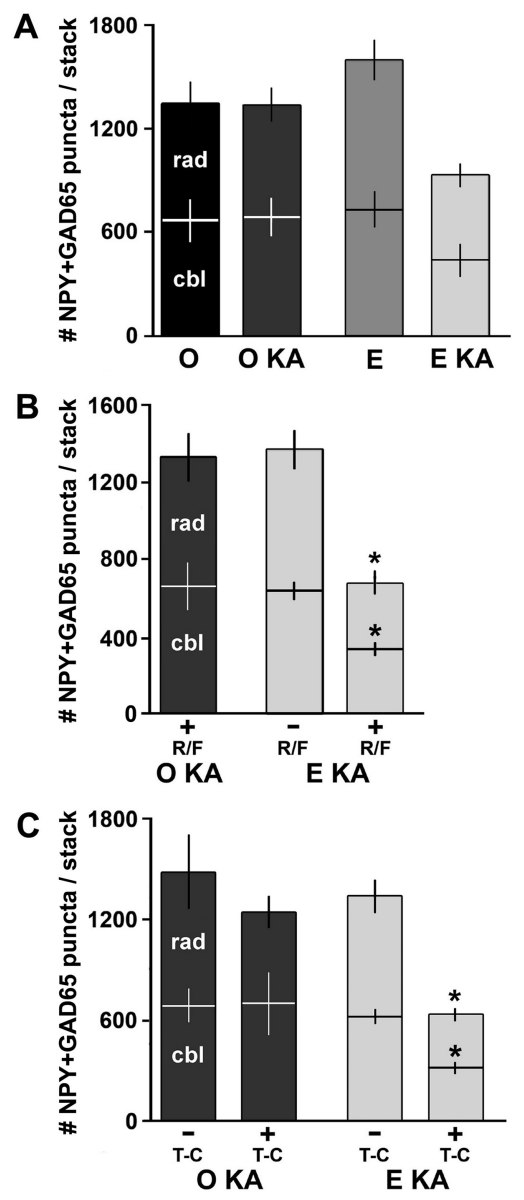

Figure 6. Specifically in estradiol-treated animals, severe seizures decrease the number of inhibitory varicosities that contain NPY. NPY + GAD65 puncta were analyzed; data are from the same image stacks as in Figure 5. $\boldsymbol{A}$, Mean \pm SEM number of NPY + GAD65 puncta per 10,870 $\mu \mathrm{m}^{3}$ image stack in control oil $(0 ; n=6)$ and estradiol $(\mathrm{E} ; n=6)$ rats and in oil $(n=7)$ and estradiol $(n=7)$ rats that experienced any stage of KA-induced seizure. $\boldsymbol{B}$, Mean \pm SEM number of NPY+GAD65 puncta per stack in 0 KA and $E$ KA rats, separating $E$ KA rats that experienced rearing/falling seizures $(+\mathrm{R} / \mathrm{F} ; n=4)$ or did not reach this stage $(-\mathrm{R} / \mathrm{F} ; n=3)$. C, Mean \pm SEM number of NPY + GAD65 puncta per stack in 0 KA and E KA animals, separating rats that experienced tonic-clonic seizures ( $+\mathrm{T}-\mathrm{C} ;$ oil, $n=3 ;$ estradiol, $n=4$ ) or did not reach this stage ( $-\mathrm{T}-\mathrm{C}$; oil, $n=4$; estradiol, $n=3$ ). Rearing/falling or T-C seizures significantly decreased the number of NPY + GAD65 puncta in estradiol animals $(p<0.05)$, whereas these seizures had no effect on puncta number in the oil group. Each bar shows separate counts from the cell body layer (cbl) and stratum radiatum (rad), which did not differ. $0 \mathrm{KA}$, 0il-KA-treated; E KA, estradiol-KA-treated. * indicates a significant difference $(p<0.05)$ from corresponding layer in $\mathrm{E} K A$ animals that did not have $\mathrm{R} / \mathrm{F}(\boldsymbol{B})$ or $\mathrm{T}-\mathrm{C}(\boldsymbol{C})$ seizures.

is present on some LDCVs. However, because dense fractions likely contain organelles in addition to LDCVs, we also investigated whether LDCVs contain $\mathrm{ER} \alpha$ using immunoelectron microscopy. Consistent with our previous observations (Hart et al., 2007), we found ER $\alpha$-IR in various extranuclear profiles, including in presynaptic boutons, where it was often associated with small clear vesicles (data not shown). Importantly however, we also found that some LDCVs in presynaptic boutons that formed symmetric (i.e., inhibitory) synapses were $\mathrm{ER} \alpha$ immunoreactive (Fig. $7 B$ ). This finding, especially together with results of cell fractionation, demonstrates unambiguously that LDCVs contain $\mathrm{ER} \alpha$ and are thus targets for direct estradiol action.

\section{Discussion}

We find that estradiol is both proconvulsant and anticonvulsant for hippocampus-dependent behavioral seizures. On one hand, estradiol increases seizure susceptibility, as evidenced by decreased latencies to KA seizure stages. On the other hand, it also decreases seizure severity, making the most severe stages of KA seizure behavior less likely to occur and shorter in duration. Although others have reported that estradiol can alter seizure susceptibility (for review, see Veliskova, 2006), that it concurrently suppresses seizure severity is a novel observation. Our findings also indicate that estradiol suppresses seizure severity by increasing the potentially releasable pool of NPY in inhibitory neurons and facilitating NPY release during seizures. The observation that $\mathrm{ER} \alpha$ is found on some LDCVs suggests that estradiol could facilitate NPY release through direct action on neuropeptidecontaining vesicles.

\section{GABA and seizure susceptibility}

Multiple lines of evidence support a role for GABAergic inhibition in regulating seizure susceptibility. Drugs that inhibit GABA synthesis or $\mathrm{GABA}_{\mathrm{A}}$ receptors cause seizures, whereas drugs that enhance GABAergic function are anticonvulsant (for review, see Rogawski and Loscher, 2004). Some genetic forms of human epilepsy are associated with $\mathrm{GABA}_{\mathrm{A}}$ receptor mutations (Baulac et al., 2001; Wallace et al., 2001) that impair receptor function (Bianchi and Macdonald, 2001). In animals, mutation of the gene for GAD65 decreases GAD activity and GABA levels in the brain and increases susceptibility to hippocampus-dependent behavioral seizures (Kash et al., 1997).

We found that the latencies to multiple stages of KA-induced seizure behavior were decreased by estradiol, including the earliest stages, staring and head waving/chewing, which involve the hippocampus selectively (Lothman and Collins, 1981; Zeng et al., 2007). As such, effects in the hippocampus likely contribute to the estradiol-induced increase in seizure susceptibility. Given the importance of GABAergic inhibition in regulating seizure susceptibility, it is likely that the estradiol-induced decrease in GABA release in the hippocampus (Rudick and Woolley, 2001; Rudick et al., 2003; Ledoux and Woolley, 2005) is a major factor in the increased seizure susceptibility we observed.

GABAergic neurons in the hippocampus can be classified by location/morphology, firing characteristics, and/or neurochemical phenotype (Freund and Buzsáki, 1996). Our previous studies, however, gave no indication that estradiol decreases GABA release from a particular subset of neurons. For example, it is unlikely that an effect on one class of cells would produce the $>30 \%$ lower evoked IPSC amplitude and miniature IPSC frequency we observed (Rudick and Woolley, 2001). Furthermore, histograms of docked vesicle number at inhibitory synapses in control and estradiol-treated animals showed no evidence of modality (Ledoux and Woolley, 2005), suggesting that estradiol decreases the number of vesicles available for release generally, rather than at a subset of synapses.

\section{NPY and seizure severity}

The effects of NPY on hippocampus-dependent seizures have been studied extensively. Infusion of NPY intracerebroventricularly shortens electrically induced afterdischarges in the subiculum (Woldbye et al., 1996), and NPY or Y2 receptor agonists suppress epileptiform activity in hippocampal slices (Klapstein and Colmers, 1997). Studies with NPY knock-out mice indicate that NPY is important in terminating severe KA seizures in vivo, with a minimal effect on seizure susceptibility. Baraban et al. (1997) found that neither the latency to initiate seizures nor the dose of KA required to induce seizures differs between wild-type and NPY knock-out mice. However, once knock-outs reach the 
rearing/falling stage, seizures last longer and often progress to death. Consistent with this, overexpression of NPY in the hippocampus decreases the duration of electrographic (Vezzani et al., 2002) or behavioral (Lin et al., 2006) KA seizures, with no effect on seizure latency [but see Richichi et al. (2004) for overexpression beyond the hippocampus]. NPY is thought to exert its anticonvulsant effects, at least in part, by decreasing $\mathrm{Ca}^{2+}$ influx (Qian et al., 1997) and suppressing glutamate release (Colmers et al., 1987) at nearby excitatory boutons. Our observation of NPY-IR in inhibitory boutons near excitatory synapses is consistent with this model.

\section{Estradiol regulation of NPY levels}

Electron microscopic immunocytochemistry for NPY and NPY + GAD65 immunofluorescence both indicated that estradiol increases the NPY content of inhibitory boutons. This could occur through changes in gene expression, stability or translation of mRNA, posttranslational processing, and/or a "storing up" of NPY through decreased nonseizure release.

The classical mechanism of estrogen action is through nuclear estrogen receptors $\mathrm{ER} \alpha$ and $\mathrm{ER} \beta$, which regulate expression of target genes. In CA1, nuclear ER $\alpha$ is found in a subset of GABAergic neurons (Hart et al., 2001), whereas there is little evidence for nuclear ER $\beta$ (Shughrue and Merchenthaler, 2001; Mitra et al., 2003). However, both ER $\alpha$ (Milner et al., 2001; Hart et al., 2007) and ER $\beta$ (Milner et al., 2005) are found extranuclearly in CA1. Interestingly, Nakamura and McEwen (2005) reported that the same estradiol treatment used here increases NPY mRNA in CA1, by $25 \%$. However, they also found that only $3-26 \%$ of NPY neurons in CA1 express nuclear ER $\alpha$. Given low levels of nuclear $\mathrm{ER} \alpha$ and $\mathrm{ER} \beta$, it is likely that estradiol regulation of NPY mRNA occurs through a non-ER-mediated transcriptional mechanism and/or changes in mRNA stability (Titolo et al., 2006).

Estradiol also might influence NPY peptide processing through regulation of the adaptor protein (AP) complexes involved in LDCV formation. For example, AP-3 constrains the size and quantal content of LDCVs (Grabner et al., 2006), and AP- $3 \delta$ expression is decreased by estradiol (Lee et al., 2004). If estradiol decreases the levels or function of AP- $3 \delta$ or other APs in hippocampus, this might increase the NPY content of inhibitory boutons by increasing the volume and/or NPY content of LDCVs. Another possibility is that estradiol stimulates LDCV transport to and/or accumulation in presynaptic boutons. For example, if estradiol decreased nonseizure release of NPY, more NPY might accumulate to be released during a seizure. This idea has an appealing parallel with estradiol's effect to decrease GABA release. However, because most evidence indicates that there is little, if any, spontaneous NPY release in nonepileptic hippocampus (Tu et al., 2005), it seems more likely that NPY accumulates in presynaptic boutons through an active mechanism.

\section{Estradiol regulation of NPY release}

Our immunofluorescence analyses indicated that, in addition to increasing the potentially releasable pool of NPY, estradiol potentiates the release of NPY during seizures. Blocking NPY in the hippocampus eliminated the estradiol-induced decrease in seizure severity, pointing to hippocampal NPY as primarily responsible for this effect.

Activity-dependent release of classical neurotransmitters such as GABA and neuropeptides such as NPY is $\mathrm{Ca}^{2+}$ dependent. Classical neurotransmitters are released from small synaptic vesicles docked at presynaptic active zones, near a high density of voltage-gated $\mathrm{Ca}^{2+}$ channels. As such, a single action potential can raise local $\mathrm{Ca}^{2+}$ levels sufficiently to trigger release. LDCVs that contain neuropeptides, however, are generally located further from active zones (Torreabla and Carrasco, 2004) and require high-frequency activity to raise $\mathrm{Ca}^{2+}$ sufficiently for release (Bartfai et al., 1988; Verhage et al., 1991). Thus, any estradiolinduced change in the bouton microenvironment that potentiates $\mathrm{Ca}^{2+}$ entry and/or brings LDCVs nearer to $\mathrm{Ca}^{2+}$ channels could facilitate NPY release. The differential effect of estradiol to facilitate activity-dependent release of NPY, and not of GABA, argues in favor of the second suggestion: that estradiol mobilizes NPY-containing LDCVs nearer to sites of $\mathrm{Ca}^{2+}$ entry.

We hypothesized that estradiol might regulate LDCVs directly. In Hart et al. (2007), we used serial section immunoelectron microscopy to show that clusters of small vesicles in inhibitory boutons are $\mathrm{ER} \alpha$ immunoreactive and that estradiol shifts the location specifically of $\mathrm{ER} \alpha$-immunoreactive vesicles within the larger vesicle pool. In the same study, confocal microscopy showed a high degree of colocalization between extranuclear $\mathrm{ER} \alpha$-IR and punctate NPY-IR, suggesting that ER $\alpha$ also might be associated with NPY-containing LDCVs. In the current study, we 
found both with cell fractionation and immunoelectron microscopy that LDCVs contain ER $\alpha$. Thus, by analogy to Hart et al. (2007), estradiol might facilitate NPY release by acting directly on LDCVs to mobilize them closer to sites of $\mathrm{Ca}^{2+}$ influx and vesicle docking/release. Although speculative, if LDCVs in other brain areas also contain steroid receptors, direct effects on LDCVs could be a generalizable mechanism for steroid regulation of neuropeptide release.

Together, our findings raise an interesting paradox: how can estradiol both suppress the release of GABA and facilitate the release of NPY? One possibility is that GABA- and NPYcontaining vesicles are influenced by different estrogen receptors (e.g., $\mathrm{ER} \alpha$ vs $\mathrm{ER} \beta$ ). Our observation of $\mathrm{ER} \alpha$ on both small vesicles and LDCVs, however, argues against this. An intriguing alternative is that the differential effect of estradiol on GABA and NPY arises from differences in the molecular composition of GABAversus NPY-containing vesicles. Although neurotransmitter vesicles and LDCVs share many molecular components (Torreabla and Carrasco, 2004), LDCVs contain some proteins not found in classical transmitter vesicles. For example, CAPS (Walent et al., 1992 ) is an LDCV-specific protein that is required for secretion (Speese et al., 2007) and may be involved in LDCV docking (Hammarlund et al., 2008). Understanding whether and how estradiol regulates CAPS or other LDCV-specific proteins in the hippocampus, interactions between $\mathrm{ER} \alpha$ and LDCV proteins, and the role(s) these proteins play in LDCV mobilization and docking, could lead to identification of novel molecular targets for anticonvulsant therapies.

\section{References}

Adams MM, Shah RA, Janssen WG, Morrison JH (2001) Different modes of hippocampal plasticity in response to estrogen in young and aged female rats. Proc Natl Acad Sci USA 98:8071-8076.

Aoki C, Pickel VM (1989) Neuropeptide Y in the cerebral cortex and the caudate-putamen nuclei: ultrastructural basis for interactions with GABAergic and non-GABAergic neurons. J Neurosci 9:4333-4354.

Azcoitia I, Sierra A, Garcia-Segura LM (1999) Localization of estrogen receptor $\beta$-immunoreactivity in astrocytes of the adult rat brain. Glia $26: 260-267$.

Backstrom T (1976) Epileptic seizures in women related to plasma estrogen and progesterone during the menstrual cycle. Acta Neurol Scand 54:321-347.

Baraban SC, Hollopeter G, Erickson JC, Schwartzkroin PA, Palmiter RD (1997) Knock-out mice reveal a critical antiepileptic role for neuropeptide Y. J Neurosci 17:8927-8936.

Bartfai T, Iverfeldt K, Fisone G, Serfozo P (1988) Regulation of the release of coexisting neurotransmitters. Annu Rev Pharmacol Toxicol 28:285-310.

Baulac S, Huberfeld G, Gourfinkel-An I, Mitropoulou G, Beranger A, Prud'homme JF, Baulac M, Brice A, Bruzzone R, LeGuern E (2001) First genetic evidence of GABA(A) receptor dysfunction in epilepsy: a mutation in the gamma2-subunit gene. Nat Genet 28:46-48.

Berwin B, Floor E, Martin TF (1998) CAPS (mammalian Unc-31) protein localizes to membranes involved in dense-core vesicle exocytosis. Neuron 21:137-145.

Bianchi MT, Macdonald RL (2001) Mutation of the $9^{\prime}$ leucine in the $\mathrm{GABA}(\mathrm{A})$ receptor gamma2L subunit produces an apparent decrease in desensitization by stabilizing open states without altering desensitized states. Neuropharmacology 41:737-744.

Colmers WF, Lukowiak K, Pittman QJ (1987) Presynaptic action of neuropeptide $\mathrm{Y}$ in area $\mathrm{CA} 1$ of the rat hippocampal slice. J Physiol 383:285-299.

El Bahh B, Balosso S, Hamilton T, Herzog H, Beck-Sickinger AG, Sperk G, Gehlert DR, Vezzani A, Colmers WF (2005) The anti-epileptic actions of neuropeptide $\mathrm{Y}$ in the hippocampus are mediated by $\mathrm{Y} 2$ and not $\mathrm{Y} 5$ receptors. Eur J Neurisci 22:1417-1430.

Freund TF, Buzsáki G (1996) Interneurons of the hippocampus. Hippocampus 6:347-470.

Grabner CP, Price SD, Lysakowski A, Cahill AL, Fox AP (2006) Regulation of large dense-core vesicle volume and neurotransmitter content mediated by adaptor protein 3. Proc Natl Acad Sci U S A 103:10035-10040.

Haas HL, Hermann A, Greene RW, Chan-Palay V (1987) Action and location of neuropeptide tyrosine $(\mathrm{Y})$ on hippocampal neurons of the rat in slice preparations. J Comp Neurol 257:208-215.

Hammarlund M, Watanabe S, Schuske K, Jorgensen EM (2008) CAPS and syntaxin dock dense core vesicles to the plasma membrane in neurons. J Cell Biol 180:483-491.

Hart SA, Patton JD, Woolley CS (2001) Quantitative analysis of ER alpha and GAD colocalization in the hippocampus of the adult female rat. J Comp Neurol 440:144-155.

Hart SA, Snyder MA, Smejkalova T, Woolley CS (2007) Estrogen mobilizes a subset of estrogen receptor- $\alpha$-immunoreactive vesicles in inhibitory presynaptic boutons in hippocampal CA1. J Neurosci 27:2102-2111.

Herzog AG, Klein P, Ransil BJ (1997) Three patterns of catamenial epilepsy. Epilepsia 38:1082-1088.

Husum H, Mikkelsen JD, Mork A (1998) Extracellular levels of neuropeptide $\mathrm{Y}$ are markedly increased in the dorsal hippocampus of freely moving rats during kainic acid-induced seizures. Brain Res 781:351-354.

Kaminski RM, Livingood MR, Rogawski MA (2004) Allopregnanolone analogs that positively modulate GABA receptors protect against partial seizures induced by $6-\mathrm{Hz}$ electrical stimulation in mice. Epilepsia $45: 864-867$

Kash SF, Johnson RS, Tecott LH, Noebels JL, Mayfield RD, Hanahan D, Baekkeskov S (1997) Epilepsy in mice deficient in the 65-kDa isoform of glutamic acid decarboxylase. Proc Natl Acad Sci U S A 94:14060-14065.

Kaufman DL, Houser CR, Tobin AJ (1991) Two forms of the gammaaminobutyric acid synthetic enzyme glatamate decarboxylase have distinct intraneuronal distributions and cofactor interactions. J Neurochem 56:720-723.

Klapstein GJ, Colmers WF (1997) Neuropeptide Y suppresses epileptiform activity in rat hippocampus in vitro. J Neurophysiol 78:1651-1661.

Ledoux VA, Woolley CS (2005) Evidence that disinhibition is associated with a decrease in number of vesicles available for release at inhibitory synapses. J Neurosci 25:971-976.

Lee JY, Kim JH, Hong SH, Lee JY, Cherny RA, Bush AI, Palmiter RD, Koh JY (2004) Estrogen decreases zinc transporter 3 expression and synaptic vesicle zinc levels in mouse brain. J Biol Chem 279:8602-8607.

Lin EJ, Young D, Baer K, Herzog H, During MJ (2006) Differential actions of NPY on seizure modulation via Y1 and Y2 receptors: evidence from receptor knockout mice. Epilepsia 47:773-780.

Lothman EW, Collins RC (1981) Kainic acid induced limbic seizures: metabolic, behavioral, electroencephalographic and neuropathological correlates. Brain Res 218:299-318.

Milner TA, Veznedaroglu E (1992) Ultrastructural localization of neuropeptide Y-like immunoreactivity in the rat hippocampal formation. Hippocampus 2:107-125.

Milner TA, McEwen BS, Hayashi S, Li CJ, Reagan LP, Alves SE (2001) Ultrastructural evidence that hippocampal alpha estrogen receptors are located at extranuclear sites. J Comp Neurol 429:355-371.

Milner TA, Ayoola K, Drake CT, Herrick SP, Tabori NE, McEwen BS, Warrier S, Alves SE (2005) Ultrastructural localization of estrogen receptor beta immunoreactivity in the rat hippocampal formation. J Comp Neurol 491:81-95.

Mitra SW, Hoskin E, Yudkovitz J, Pear L, Wilkinson HA, Hayashi S, Pfaff DW, Ogawa S, Rohrer SP, Schaeffer JM, McEwen BS, Alves SE (2003) Immunolocalization of estrogen receptor beta in the mouse brain: comparison with estrogen receptor alpha. Endocrinology 144:2055-2067.

Nakamura NH, McEwen BS (2005) Changes in interneuronal phenotypes regulated by estradiol in the adult rat hippocampus: a potential role for neuropeptide Y. Neuroscience 136:357-369.

Navone F, Di Gioia G, Jahn R, Browning M, Greengard P, De Camilli P (1989) Microvesicles of the neurohypophysis are biochemically related to small synaptic vesicles of presynaptic nerve terminals. J Cell Biol 109:3425-3433.

Qian J, Colmers WF, Saggau P (1997) Inhibition of synaptic transmission by neuropeptide $\mathrm{Y}$ in rat hippocampal area CA1: modulation of presynaptic $\mathrm{Ca}^{2+}$ entry. J Neurosci 17:8169-8177.

Racine RJ (1972) Modification of seizure activity by electrical stimulation: II. Motor seizure. Electroencephalogr Clin Neurophysiol 32:281-294.

Richichi C, Lin EJ, Stefanin D, Colella D, Ravizza T, Grignaschi G, Veglianese P, Sperk G, During MJ, Vezzani A (2004) Anticonvulsant and antiepi- 
leptogenic effects mediated by adeno-associated virus vector neuropeptide Y expression in the rat hippocampus. J Neurosci 24:3051-3059.

Rogawski MA, Loscher W (2004) The neurobiology of antiepileptic drugs. Nat Rev Neurosci 5:553-564.

Rudick CN, Woolley CS (2001) Estrogen regulates functional inhibition of hippocampal CA1 pyramidal cells in the adult female rat. J Neurosci 21:6532-6543.

Rudick CN, Gibbs RB, Woolley CS (2003) A role for the basal forebrain cholinergic system in estrogen-induced disinhibition of hippocampal pyramidal cells. J Neurosci 23:4479-4490.

Saegusa C, Fukuda M, Mikoshiba K (2002) Synaptotagmin V is targeted to dense-core vesicles that undergo calcium-dependent exocytosis in PC12 cells. J Biol Chem 277:24499-24505.

Shughrue PJ, Merchenthaler I (2001) Distribution of estrogen receptor beta immunoreactivity in the rat central nervous system. J Comp Neurol 436:64-81.

Smith CC, McMahon LL (2005) Estrogen-induced increase in the magnitude of long-term potentiation occurs only when the ratio of NMDA transmission to AMPA transmission is increased. J Neurosci 25:7780-7791.

Smith MC, Freeman ME, Neill JD (1975) The control of progesterone secretion during the estrous cycle and early pseudopregnancy in the rat: prolactin, gonadotropin and steriod levels associated with rescue of the corpus luteum of pseudopregnancy. Endocrinology 96:219-226.

Smith SS, Gong QH, Hsu FC, Markowitz RS, ffrench-Mullen JM, Li X (1998) GABA(A) receptor alpha4 subunit suppression prevents withdrawal properties of an endogenous steroid. Nature 392:926-930.

Speese S, Petrie M, Schuske K, Ailion M, Ann K, Iwasaki K, Jorgenson EM, Martin TF (2007) UNC 31 (CAPS) is required for dense-core vesicle but not synaptic vesicle exocytosis in Caenorhabditis elegans. J Neurosci 27:6150-6162.

Speidel D, Varoqueaux F, Enk C, Nojiri M, Grishanin RN, Martin TFJ, Hofmann K, Brose N, Reim K (2003) A family of $\mathrm{Ca}^{2+}$-dependent activator proteins for secretion. J Biol Chem 278:52802-52809.

Sperk G, Lassman H, Baran H, Seitelberger F, Hornykiewicz O (1985) Kainic acid-induced seizures: dose-relationship of behavioural, neurochemical and histopathological changes. Brain Res 338:289-295.

Tandon A, Bannykh S, Kowalchyk JA, Banerjee A, Martin TFJ, Balch WE (1998) Differential regulation of exocytosis by calcium and CAPS in semi-intact synaptosomes. Neuron 21:147-154.

Titolo D, Cai F, Belsham DD (2006) Coordinate regulation of neuropeptide $\mathrm{Y}$ and agouti-related peptide gene expression depends on the ratio of estrogen receptor (ER)alpha to ERbeta in clonal hypothalamic neurons. Mol Endocrinol 20:2080-2092.

Torreabla F, Carrasco MA (2004) A review on electron microscopy and neurotransmitter systems. Brain Res Rev 47:5-17.

Tu B, Timofeeva O, Jiao Y, Nadler JV (2005) Spontaneous release of neuropeptide $\mathrm{Y}$ tonically inhibits recurrent mossy fiber synaptic transmission in epileptic brain. J Neurosci 25:1718-1729.

Veliskova J (2006) The role of estrogens in seizures and epilepsy: the bad guys or the good guys?. Neuroscience 138:837-844.
Veliskova J, Velisek L (2007) 17 $\beta$-Estradiol increases dentate gyrus inhibition in female rats via augmentation of hilar neuropeptide Y. J Neurosci 27:6054-6063.

Verhage M, McMahon HT, Ghijsen WE, Boomsma F, Scholten G, Wiegant VM, Nicholls DG (1991) Differential release of amino acids, neuropeptides, and catecholamines from isolated nerve terminals. Neuron 6:517-524.

Vezzani A, Michalkiewicz M, Michalkiewicz T, Moneta D, Ravizza T, Richichi C, Aliprandi M, Mule F, Pirona L, Gobbi M, Schwarzer C, Sperk G (2002) Seizure susceptibility and epileptogenesis are decreased in transgenic rats overexpressing neuropeptide Y. Neuroscience 110:237-243.

Walch-Solimena C, Takei K, Marek KL, Midyett K, Sudhof TC, De Camilli P, Jahn R (1993) Synaptotagmin: A membrane constituent of neuropeptide-containing large dense-core vesicles. J Neurosci 13:3895-3903.

Walent JH, Porter BW, Martin TF (1992) A novel $145 \mathrm{kd}$ brain cytosolic protein reconstitutes $\mathrm{Ca}^{2+}$-regulated secretion in permeable neuroendocrine cells. Cell 70:765-775.

Wallace RH, Marini C, Petrou S, Harkin LA, Bowser DN, Panchal RG, Williams DA, Sutherland GR, Mulley JC, Scheffer IE, Berkovic SF (2001) Mutant GABA(A) receptor gamma2-subunit in childhood absence epilepsy and febrile seizures. Nat Genet 28:49-52.

Weinshenker D, Szot P, Miller NS, Rust NC, Hohmann JG, Pyati U, White SS, Palmiter RD (2001) Genetic comparison of seizure control by norepinephrine and neuropeptide Y. J Neurosci 21:7764-7769.

Willoughby JO, Mackenzie L, Medvedev A, Hiscock JJ (1997) Fos induction following systemic kainic acid: early expression in hippocampus and later widespread expression correlated with seizure. Neuroscience 77:379-392.

Woldbye DP, Madsen TM, Larsen PJ, Mikkelsen JD, Bolwig TG (1996) Neuropeptide $Y$ inhibits hippocampal seizures and wet dog shakes. Brain Res 737:162-168.

Woldbye DP, Larsen PJ, Mikkelsen JD, Klemp K, Madsen TM, Bolwig TG (1997) Powerful inhibition of kainic acid seizures by neuropeptide $Y$ via Y5-like receptors. Nat Med 3:761-764.

Woolley CS, (2000) Estradiol facilitates kainic acid-induced, but not flurothyl-induced, behavioral seizure activity in adult female rats. Epilepsia 41:510-515.

Woolley CS, McEwen BS (1992) Estradiol mediates fluctuation in hippocampal synapse density during the estrous cycle in the adult rat. J Neurosci 12:2549-2554.

Woolley CS, McEwen BS (1993) Roles of estradiol and progesterone in regulation of hippocampal dendritic spine density during the estrous cycle in the rat. J Comp Neurol 336:293-306.

Yankova M, Hart SA, Woolley CS (2001) Estrogen increases synaptic connectivity between single presynaptic inputs and multiple postsynaptic CA1 pyramidal cells: a serial electron-microscopic study. Proc Natl Acad Sci USA 98:3525-3530.

Zeng L-H, Xu L, Rensing NR, Sinatra PM, Rothman SM, Wong M (2007) Kainate seizures cause acute dendritic injury and actin depolymerization in vitro. J Neurosci 27:11604-11613. 